\title{
The Product of Matrix Metalloproteinase Cleavage of Doxorubicin Conjugate for Anticancer Drug Delivery: Calorimetric, Spectroscopic, and Molecular Dynamics Studies on Peptide-Doxorubicin Binding to DNA
}

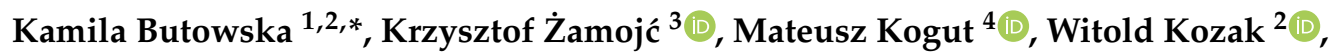 \\ Dariusz Wyrzykowski ${ }^{3}$, Wiesław Wiczk ${ }^{5}{ }^{(}$, Jacek Czub ${ }^{4}\left(\mathbb{D}\right.$, Jacek Piosik ${ }^{1}\left(\mathbb{D}\right.$ and Janusz Rak ${ }^{2}(\mathbb{D}$ \\ 1 Laboratory of Biophysics, Intercollegiate Faculty of Biotechnology University of Gdańsk and Medical \\ University of Gdańsk, Abrahama 58, 80-307 Gdańsk, Poland; jacek.piosik@biotech.ug.edu.pl \\ 2 Department of Physical Chemistry, Faculty of Chemistry, University of Gdańsk, Wita Stwosza 63, \\ 80-308 Gdańsk, Poland; davelombardo@wp.pl (W.K.); janusz.rak@ug.edu.pl (J.R.) \\ 3 Department of General and Inorganic Chemistry, Faculty of Chemistry, University of Gdańsk, \\ Wita Stwosza 63, 80-308 Gdańsk, Poland; krzysztof.zamojc@ug.edu.pl (K.Ż.); \\ dariusz.wyrzykowski@ug.edu.pl (D.W.) \\ 4 Department of Physical Chemistry, Faculty of Chemistry, Gdańsk University of Technology, \\ Narutowicza 11/12, 80-233 Gdańsk, Poland; giggsmk@op.pl (M.K.); jacek.czub@pg.edu.pl (J.C.) \\ 5 Department of Biomedical Chemistry, Faculty of Chemistry, University of Gdańsk, Wita Stwosza 63, \\ 80-308 Gdańsk, Poland; wieslaw.wiczk@ug.edu.pl \\ * Correspondence: kamila.butowska@phdstud.ug.edu.pl; Tel.: +48-58-523-6310
}

Received: 29 July 2020; Accepted: 18 September 2020; Published: 21 September 2020

\begin{abstract}
Matrix metalloproteinases (MMPs) are extracellular matrix degradation factors, promoting cancer progression. Hence, they could provide an enzyme-assisted delivery of doxorubicin (DOX) in cancer treatment. In the current study, the intercalation process of DOX and tetrapeptide-DOX, the product of the MMPs' cleavage of carrier-linked DOX, into dsDNA was investigated using stationary and time-resolved fluorescence spectroscopy, UV-Vis spectrophotometry and isothermal titration calorimetry (ITC). The molecular dynamics (MD) simulations on the same tetrapeptide-DOX $\cdots$ DNA and DOX $\cdots$ DNA systems were also performed. The undertaken studies indicate that DOX and tetrapeptide-DOX can effectively bond with dsDNA through the intercalation mode; however, tetrapeptide-DOX forms less stable complexes than free DOX. Moreover, the obtained results demonstrate that the differences in DNA affinity of both forms of DOX can be attributed to different intercalation modes. Tetrapeptide-DOX shows a preference to intercalate into DNA through the major groove, whereas DOX does it through the minor one. In summary, we can conclude that the tetrapeptide-DOX intercalation to DNA is significant and that even the lack of non-specific proteases releasing DOX from the tetrapeptide conjugate, the presence of which is suggested by the literature for the efficient release of DOX, should not prevent the cytostatic action of the anthracycline.
\end{abstract}

Keywords: doxorubicin; matrix metalloproteinases; intercalation; DNA; cleavable peptide; drug delivery

\section{Introduction}

Cancer-the second leading cause of death worldwide — can be treated by several modalities, of which chemotherapy represents $36 \%$ of the treatment options [1,2]. Anthracyclines are one of the most widely used chemotherapeutic drugs for the treatment of various types of cancer including leukemia, melanoma, Kaposi's sarcoma, and solid tumors, e.g., breast or prostate [3,4]. Doxorubicin (DOX) is one 
of the well-known anthracycline antibiotics, which was isolated in the 1960s from a mutated variant of Streptomyces peucetius (var. S. caesius) [5]. It is an important chemotherapeutic agent with a wide spectrum of activity $[3,6,7]$. The mechanism of DOX action is related to its intercalation into cellular DNA leading to the inhibition of the synthesis of macromolecules, DNA cross-linking, and alkylation, as well as the generation of free radicals and the inhibition of topoisomerase II [8-10]. Despite its clinical efficacy, it has severe disadvantages, including cardiotoxicity and myelosuppression [11,12]. Moreover, DOX can lead to several side effects that mainly affect the brain, kidneys, and liver [13].

One of the strategies to increase therapeutic efficiency, with high binding specificity and reduced toxic effects of a drug, is to conjugate it with polymers, lipid nanoparticles, or antibody-drug conjugates [14-16]. Such an approach can lead to a system characterized by enhanced solubility, permeability, and retention in body plasma that triggers drug release in cancer cells [17]. A variety of polymers, including polymer-drug conjugates (PDCs), polymer-protein/peptide, polymer-DNA, and their hybrids, have been developed in the past decades as selective therapeutic agents. Several examples of PDCs have been observed to couple a hydrophobic drug with hydrophilic polymers such as poly(lactic-co-glycolic acid) (PLGA) and poly(ethylene glycol) (PEG) $[18,19]$. However, PDCs with increased stability, solubility, and lower toxicity would not be suitable for cancer therapy if they did not release an anticancer component at the target place. To overcome this problem, PDCs release a drug using a peptide fragment selectively cleaved by enzymes, or under specific conditions [20]. Matrix metalloproteinases (MMPs) are a group of over 20 proteolytic enzymes characterized by their ability to remodel and degrade the extracellular matrix [21]. MMPs are overexpressed in newly formed tumor tissues, thereby promoting angiogenesis, and are involved in cancer progression; MMP-2 and MMP-9, in particular, play a critical role in this process [22,23]. Therefore, MMPs could constitute a promising strategy for targeted therapeutic agent delivery via an enzyme-triggered release mechanism [24]. According to the literature, there are a series of substrate peptide sequences degradable in the presence of MMPs, e.g., Gly-Pro-Leu-Gly-Ile-Ala-Gly-Gln, Pro-Val-Gly-Leu-Ile-Gly, or Pro-Leu-Gly-Val-Arg, where cleavage occurs between leucine (Leu) and glycine (Gly) [25-27]. Using this approach, new polymer-drug conjugates with a selective peptide sequence between the carrier (polymer) and the cargo (drug) have been designed [28]. The drug release from enzymatically cleavable prodrugs occurs within a two-step mechanism: (1) a prodrug is cleaved by MMPs and is (2) further cleaved or hydrolyzed to the desired drug [29]. Hence, some reports suggest that additional proteases are important for liberating a free drug from intermediate cleavage products [30].

In this study, we present the synthesis of a tetrapeptide-DOX conjugate (Leu-Ala-Gly-Gly-DOX, i.e., 4-pep-DOX), as a potential result of MMPs' action on the substrate peptide sequence (Figure 1). The selected MMP-2/-9-cleavable peptide, containing the Leu-Gly sequence, was expanded to Gly-Pro-Leu-Gly-Leu-Ala-Gly-Gly, which is cleavable by the chosen MMPs' domain [31]. We demonstrated the impact of the presence of the tetrapeptide fragment in 4-pep-DOX on its intercalating properties to dsDNA, and compared the tetrapeptide-DOX $\cdots$ dsDNA complex with free doxorubicin, namely DOX $\cdots$ dsDNA. The characteristics of the dsDNA complex with 4-pep-DOX and DOX were studied by spectrophotometric titration, steady-state, and time-resolved fluorescence spectroscopy, as well as isothermal titration calorimetry (ITC). Furthermore, molecular dynamics (MD) simulations were carried out to determine the preferred binding sites to dsDNA. To the best of our knowledge, this is the first report where an MMP-cleavable product (Leu-Ala-Gly-Gly-DOX) has been characterized at the molecular level. 


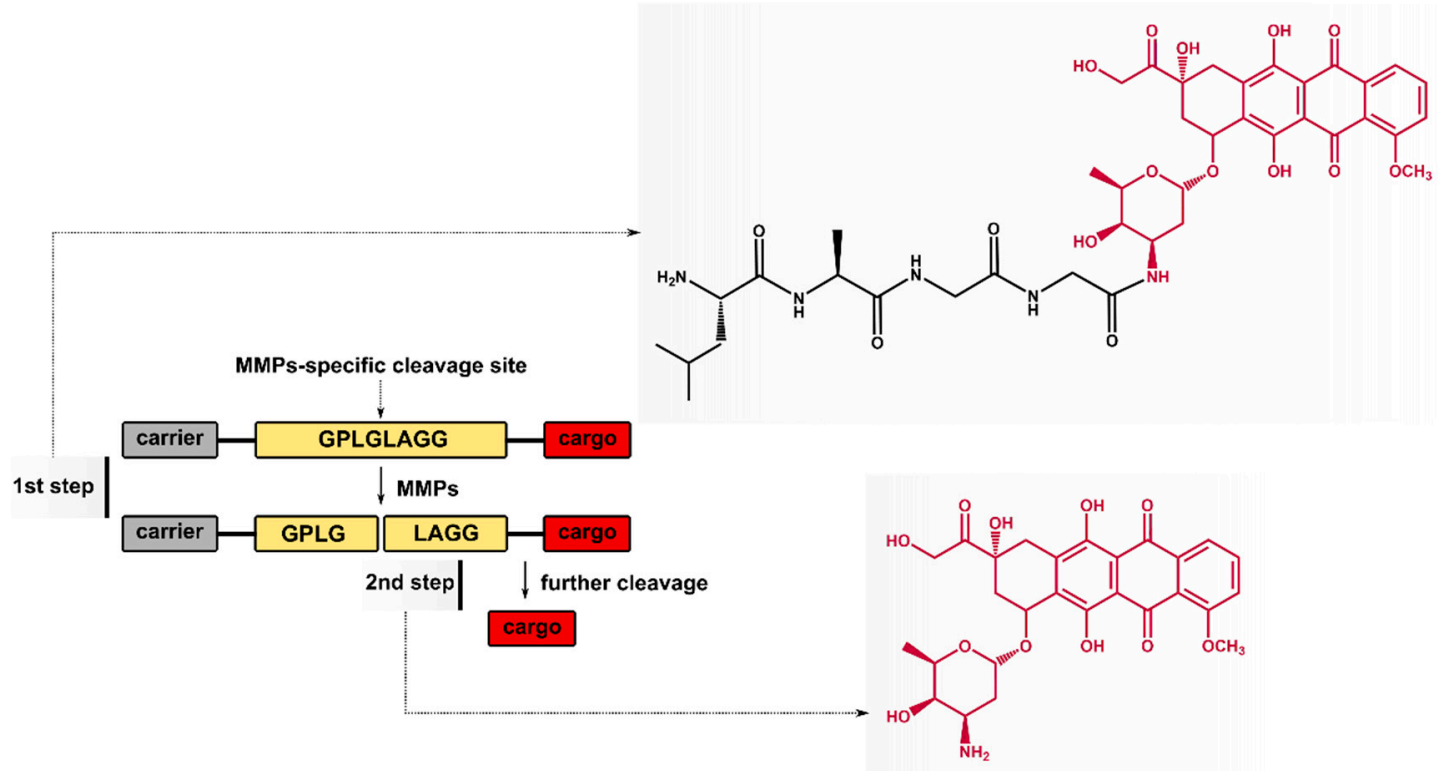

Figure 1. Doxorubicin (DOX) release strategies for matrix metalloproteinase (MMP)-cleavable prodrugs.

\section{Results and Discussion}

\subsection{Cleavage of Peptide by MMPs}

The MMP-2/-9-cleavable peptide was degraded by collagenase IV (containing MMP-2/-9) in a time-dependent manner. The MMPs' substrate specificity, revealed by the MS analysis, is consistent with that reported previously and indicates that the proposed octapeptide can be responsive to MMPs [32,33]. The MALDI TOF spectrum proved that the octapeptide was cleaved between leucine (Leu) and glycine (Gly), yielding two products, namely Fmoc-Gly-Pro-Leu-Gly and Leu-Ala-Gly-Gly (see Figure S1, Supplementary Materials). Consistently, the HPLC chromatogram (Figure 2A) shows two peaks from the enzymatic digestion-the substrate, Fmoc-Gly-Pro-Leu-Gly-Leu-Ala-Gly-Gly, and the product, Fmoc-Gly-Pro-Leu-Gly, at 10.30 and $10.04 \mathrm{~min}$, respectively. During incubation, the Fmoc-Gly-Pro-Leu-Gly peak significantly increased, whereas the octapeptide peak disappeared. After $12 \mathrm{~h}$ of incubation, $17.43 \%$ of the substrate and $82.42 \%$ of the MMP-2/-9 cleaved product were observed. In order to investigate how fast the octapeptide cleaved, the aliquots were removed after 2, 8 , and $12 \mathrm{~h}$. After $2 \mathrm{~h}$ of incubation, 52.54\% of Fmoc-Gly-Pro-Leu-Gly was detected and after $8 \mathrm{~h}$ it increased to $69.53 \%$ (Figure 2B). The efficiency of the enzymatic digestion reached $82.42 \%$ after $12 \mathrm{~h}$ of incubation. The results proved that the octapeptide can be cleaved by collagenase IV and that the amount of product formed increases with the incubation time.

\subsection{Synthesis of Tetrapeptide-DOX}

In order to synthesize the desired conjugate, we performed a two-step procedure (Figure 3). First, Fmoc-Leu-Ala-Gly-Gly was coupled with DOX using the mixed anhydride method. For this purpose, Fmoc-Leu-Ala-Gly-Gly was treated with isobutyl chloroformate in the presence of triethylamine in DMF, followed by the addition of DOX (obtained independently by the reaction of DOX hydrochloride with TEA in DMF). The so-obtained raw Fmoc-Leu-Ala-Gly-Gly-DOX was purified by preparative column chromatography. In the second step, Fmoc-Leu-Ala-Gly-Gly-DOX was deprotected with a 50\% morpholine solution in DMF, furnishing raw Leu-Ala-Gly-Gly-DOX, which was finally isolated with the HPLC system and proved by MALDI TOF/TOF (see Figure S2, Supplementary Materials). It is worth mentioning that we had tested two different deprotection methods with 1,8-diazabicyclo[5.4.0]undec-7-ene (DBU) and piperidine, respectively. In both cases, we struggled through some difficulties. As far as DBU is concerned, dibenzofulvene is released during the reaction, 
which readily reacts, as an electrophile, with $\mathrm{N}$-terminal amino acid residue leading to undesired by-products [34]. When it came to piperidine, we obtained the desired product in a very poor yield, which could be due to the presumed dealkylation properties of piperidine (DOX possesses a methoxyl function in its constitution) [35].

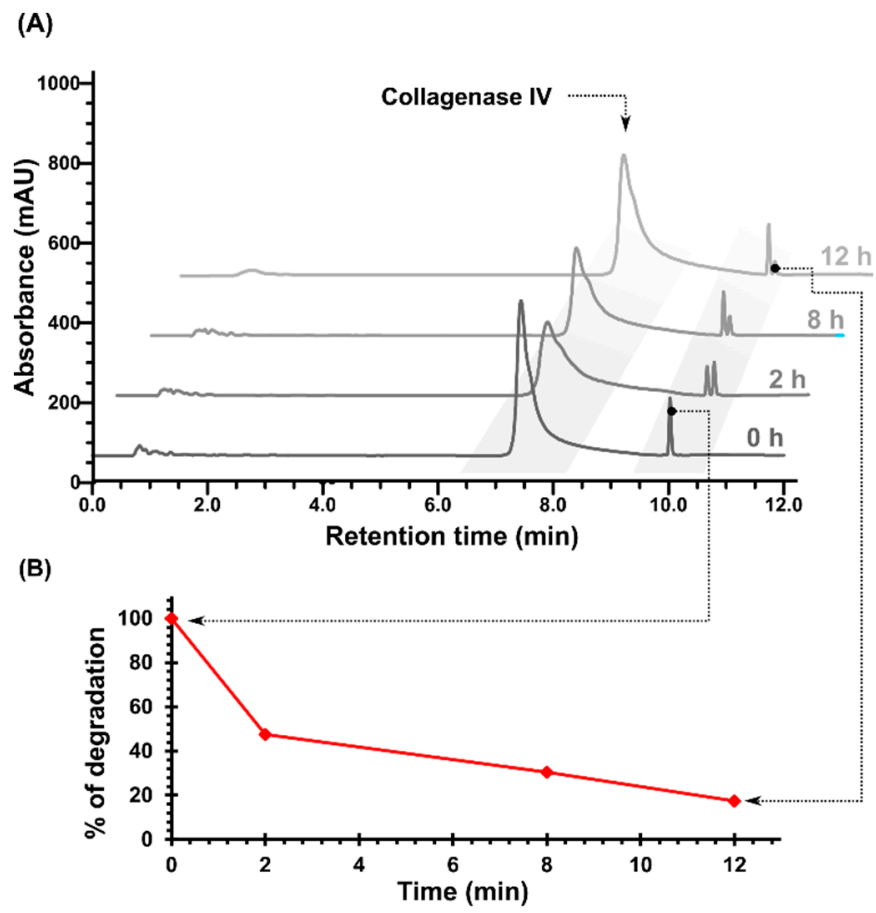

Figure 2. (A) HPLC chromatograms of the MMP-2/-9-cleavable peptide after 2, 8, and $12 \mathrm{~h}$ of incubation with collagenase IV. (B) The curves depicting the efficacy of enzymatic cleavage, triggered in a time-dependent manner.

\subsection{Spectrophotometric Titrations}

In order to evaluate the binding strength of DOX and 4-pep-DOX to dsDNA, the binding/association constants $\left(\mathrm{K}_{\mathrm{A}}\right)$ of the resulting complexes were determined from the changes in absorbance of DOX and 4-pep-DOX bands with increasing amounts of dsDNA (Figure 4). The intrinsic association constants $\left(\mathrm{K}_{\mathrm{A}}\right)$ of the complexes were calculated according to the Benesi-Hildebrand equation:

$$
\frac{\mathrm{A}_{0}}{\mathrm{~A}-\mathrm{A}_{0}}=\frac{\varepsilon_{\mathrm{f}}}{\varepsilon_{\mathrm{b}}-\varepsilon_{\mathrm{f}}}+\frac{\varepsilon_{\mathrm{f}}}{\varepsilon_{\mathrm{b}}-\varepsilon_{\mathrm{f}}} \cdot \frac{1}{\mathrm{~K}_{\mathrm{A}}[\mathrm{DNA}]},
$$

where $\mathrm{A}_{0}$ and $\mathrm{A}$ are the absorbances of DOX/4-pep-DOX in the absence and presence of dsDNA in the solution, respectively, $\varepsilon_{\mathrm{f}}$ and $\varepsilon_{\mathrm{b}}$ correspond to the extinction coefficients of free and bound ligands, respectively, while [DNA] is the concentration of dsDNA. The ligand-dsDNA binding constants were calculated from the ratio of the intercept to the slope of the linear equation of the plot of $\frac{A_{0}}{A-A_{0}}$ (measured at $480 \mathrm{~nm}$ ) to $\frac{1}{[\mathrm{DNA}]}$, and were determined to be $\mathrm{K}_{\mathrm{A}} \mathrm{DOx} \cdots$ dsDNA $=1.10 \times 10^{6} \mathrm{M}^{-1}$ and $\mathrm{K}_{\mathrm{A} \text { 4-pep-DOX }} \cdots$ dsDNA $=0.54 \times 10^{6} \mathrm{M}^{-1}$. The free energies of the binding $(\Delta \mathrm{G})$ were calculated using the standard thermodynamic relationship, $\Delta \mathrm{G}=-\mathrm{RT} \ln \mathrm{K}_{\mathrm{A}}$, and were determined to be $\Delta \mathrm{G}_{\mathrm{DOX}}{ }^{\cdots}$ dsDNA $=-8.23 \mathrm{kcal} / \mathrm{mol}$ and $\Delta \mathrm{G}_{4-\text { pep-DOX }} \cdots$ dsDNA $=-7.81 \mathrm{kcal} / \mathrm{mol}$. 


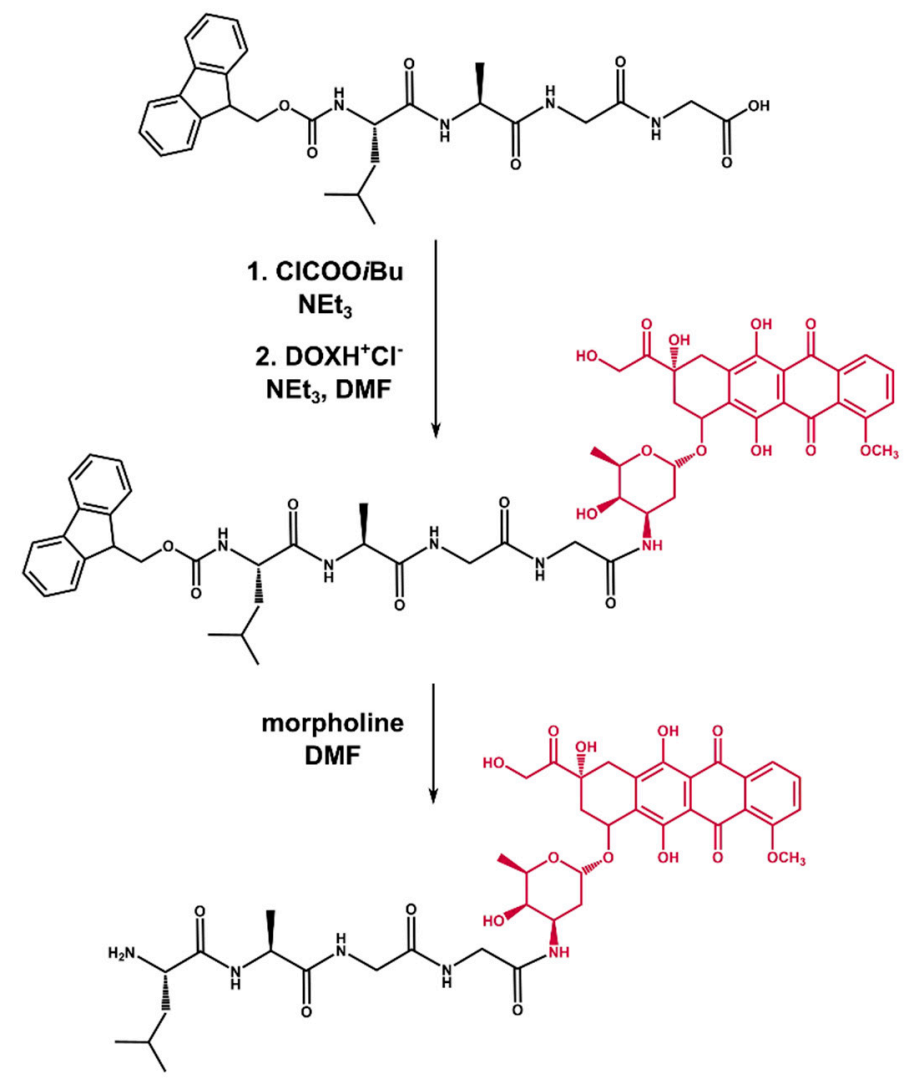

Figure 3. Synthesis scheme of the Leu-Ala-Gly-Gly-DOX conjugate.
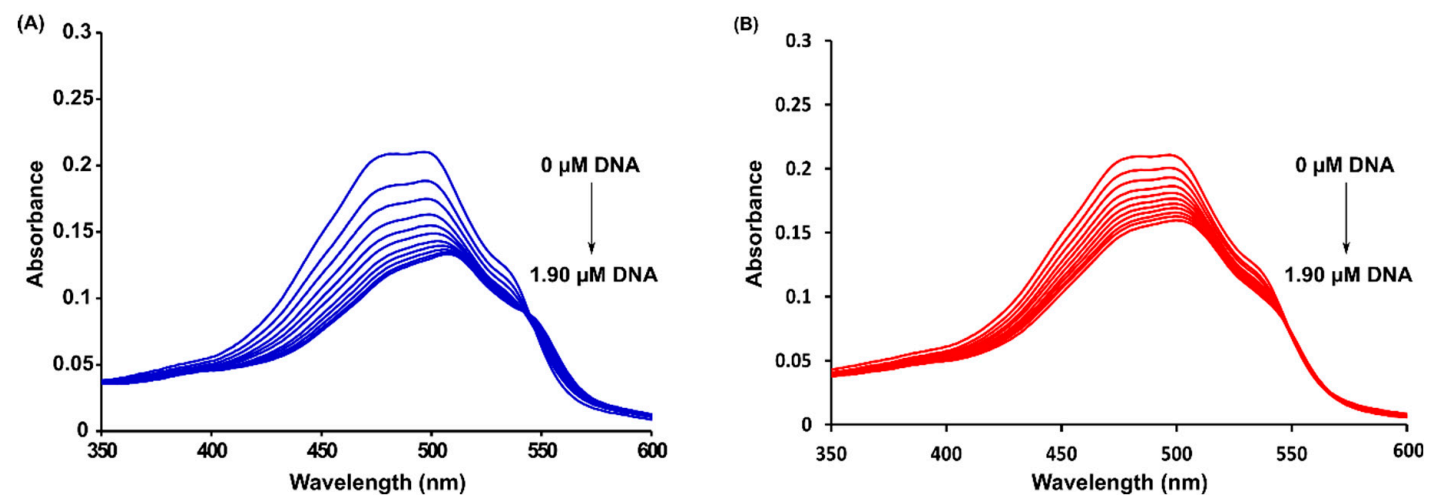

Figure 4. UV-Vis absorption spectra of DOX (A) and 4-pep-DOX (B) in the presence of dsDNA at various concentrations in $10 \mathrm{mM}$ Tris- $\mathrm{HCl}$ buffer $\left(\mathrm{pH}\right.$ 7.2) at $25^{\circ} \mathrm{C}$ (the initial concentration of DOX and 4-pep-DOX = $18 \mu \mathrm{M})$.

\subsection{Steady-State and Time-Resolved Spectroscopy}

Figure 5 shows the fluorescence emission spectra of DOX and 4-pep-DOX recorded in the presence of various dsDNA concentrations, using drug excitation at $490 \mathrm{~nm}$. It can be observed that the fluorescence intensity of both drugs decreases regularly with the increasing concentration of dsDNA, which may result from a variety of processes such as excited state reactions, ground-state complex formations, or collisional processes. 
(A)

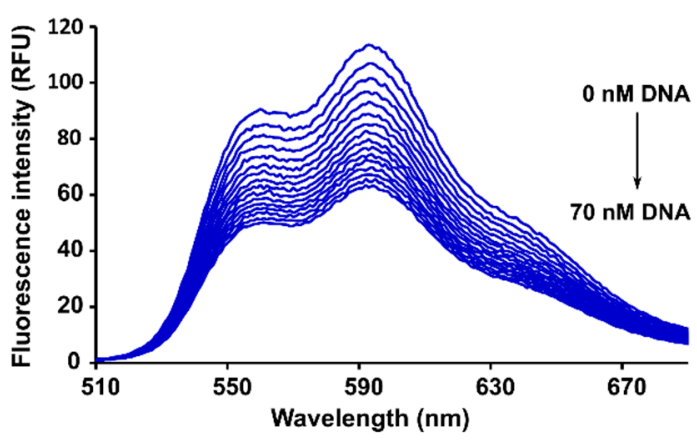

(B)

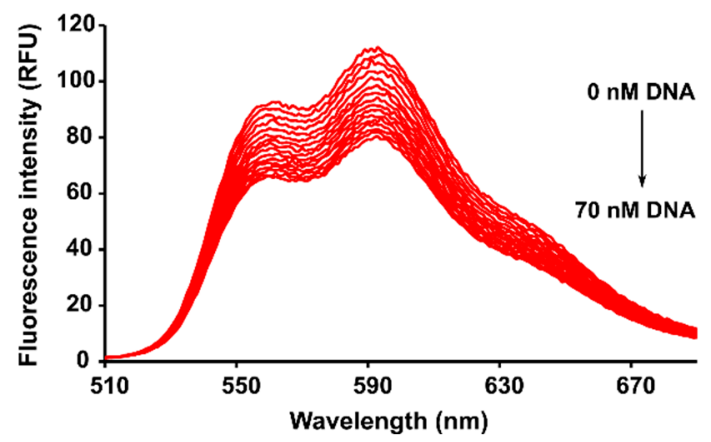

Figure 5. Fluorescence emission spectra of DOX (A) and 4-pep-DOX (B) in the presence of dsDNA at various concentrations in $10 \mathrm{mM}$ Tris- $\mathrm{HCl}$ buffer ( $\mathrm{pH}$ 7.2) at $25^{\circ} \mathrm{C}$ (the initial concentration of DOX and 4-pep-DOX = $1.94 \mu \mathrm{M})$.

In order to confirm the quenching mechanism, the fluorescence quenching was analyzed according to the Stern-Volmer equation:

$$
\frac{F_{0}}{F}=1+K_{S V}[Q]=1+k_{q} \tau_{0}[Q],
$$

where $F_{0}$ and $F$ are the fluorescence intensities in the absence and presence of quencher, [Q] is the quencher concentration, $K_{S V}$ is the Stern-Volmer quenching constant, $k_{q}$ is the bimolecular quenching rate constant, while $\tau_{0}$ is the lifetime of the fluorophore in the absence of quencher [36]. The graphs of $\frac{F_{0}}{F}$ versus $[Q]$ plotted according to the Stern-Volmer equation are shown in Figure 6. It can be observed that straight lines were obtained for both drug-DNA complexes, indicating that, in the investigated range of concentrations, the quenching is purely static or dynamic. Since the $\tau_{0}$ values for free DOX and 4-pep-DOX around neutral $\mathrm{pH}$ were determined to be $1.057 \mathrm{~ns}$ and $1.076 \mathrm{~ns}$, respectively (see below), the values of the bimolecular quenching rate constants $\left(k_{q}\right)$ are $9.37 \times 10^{15} \mathrm{M}^{-1} \mathrm{~s}^{-1}$ for DOX $\cdots$ dsDNA and $5.20 \times 10^{15} \mathrm{M}^{-1} \mathrm{~s}^{-1}$ for 4-pep-DOX $\cdots$ dsDNA complexes. As these values are much larger than the maximum scatter collision quenching constant $\left(2.0 \times 10^{10} \mathrm{M}^{-1} \mathrm{~s}^{-1}\right)$ [37], this indicates that the fluorescence quenching effects of DOX and 4-pep-DOX by dsDNA are not initiated by dynamic collisions, but rather caused by the formation of ground-state complexes.

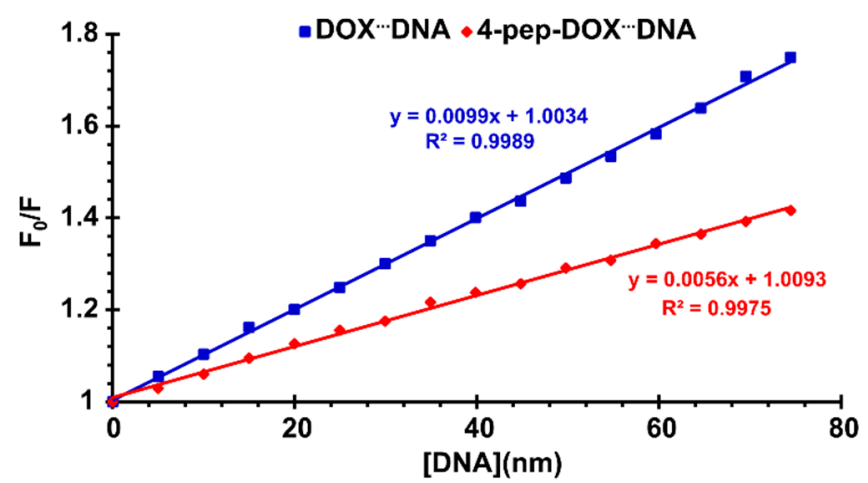

Figure 6. Stern-Volmer plots for the DOX $\cdots$ dsDNA and 4-pep-DOX $\cdots$ dsDNA systems in $10 \mathrm{mM}$ Tris- $\mathrm{HCl}$ buffer ( $\mathrm{pH} 7.2)$ at $25^{\circ} \mathrm{C}$.

Given that the fluorescence quenching of both DOX and 4-pep-DOX by dsDNA is static, the dissociation constants $\left(K_{D}\right)$ of the newly formed complexes can be determined by the Lineweaver-Burk formula [38]:

$$
\frac{1}{F_{0}-F}=\frac{1}{F_{0}}+\frac{K_{D}}{F_{0}[0]}
$$


The Lineweaver-Burk double-reciprocal plots were constructed based on the relationship of $\frac{F_{0}}{F_{0}-F}$ vs. $\frac{1}{[\mathrm{DNA}]}$ (Figure 7).

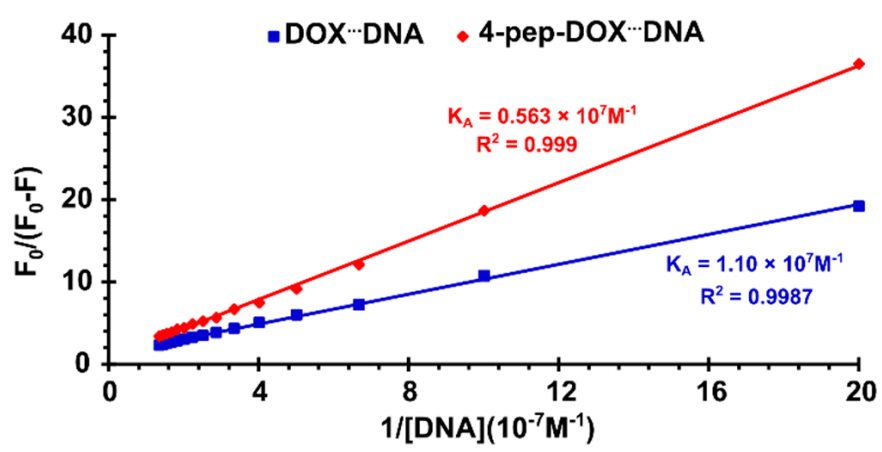

Figure 7. Lineweaver-Burk double-reciprocal curves of $\frac{F_{0}}{F_{0}-F}$ vs. $\frac{1}{[\mathrm{DNA}]}$ for the DOX $\cdots$ dsDNA and 4-pep-DOX $\cdots$ dsDNA systems in $10 \mathrm{mM}$ Tris- $\mathrm{HCl}$ buffer ( $\mathrm{pH} 7.2$ ) at $25^{\circ} \mathrm{C}$.

From the regression analysis, the association constants $\left(\mathrm{K}_{\mathrm{A}}=\mathrm{K}_{\mathrm{D}}^{-1}\right)$ between dsDNA and both studied drugs were determined to be $\mathrm{K}_{\mathrm{A} D O x}{ }^{\cdots}$ dsDNA $=1.10 \times 10^{7} \mathrm{M}^{-1}$ and $\mathrm{K}_{\mathrm{A}}$ 4-pep-DOx ${ }^{\cdots}$ dsDNA $=0.56 \times 10^{7} \mathrm{M}^{-1}$ (as the averages of two independent experiments), respectively. The observed discrepancies between the $\mathrm{K}_{\mathrm{A}}$ values obtained from spectrophotometric and spectrofluorometric titrations may result from the specificity of each method, as well as from differences in the experimental conditions (i.e., concentrations). By comparing the measured association constants, it is clear that both DOX and 4-pep-DOX show a high affinity to dsDNA; however, the complexes formed by DOX are slightly more stable compared to those of 4-pep-DOX. When small molecules bind independently to a set of equivalent sites on a macromolecule, the number of binding sites $(n)$ can be found from the following Scatchard equation [39]:

$$
\log \left[\frac{F_{0}-F}{F}\right]=\log K_{A}+n \log [Q],
$$

The plots of $\log \left[\frac{F_{0}-F}{F}\right]$ vs. $\log [Q]$ for both DOX and 4-pep-DOX are shown in Figure 8. It can be observed that the $n$ values, determined as the slopes of the straight-line plots, were found to be approximately 1.0 for both ligands that are bound per dsDNA molecule. Furthermore, the association constants estimated by this method are basically in accordance with those obtained by the Lineweaver-Burk equation $\left(\mathrm{K}_{\mathrm{A} \text { DOx }} \cdots\right.$ dsDNA $>\mathrm{K}_{\mathrm{A}} 4$-pep-DOx $\cdots$ dsDNA).

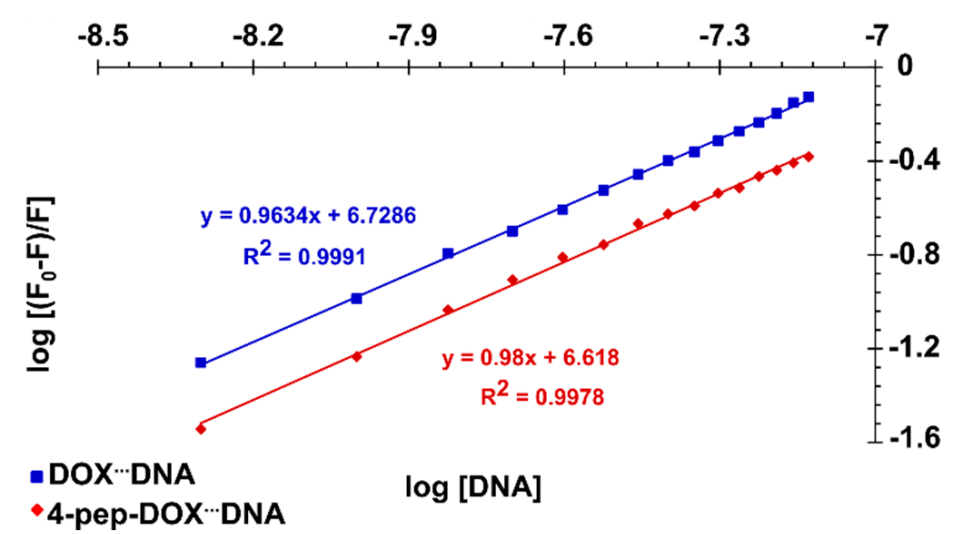

Figure 8. Plots of $\log \left[\frac{F_{0}-F}{F}\right]$ vs. $\log [\mathrm{DNA}]$ for the DOX $\cdots$ dsDNA and 4-pep-DOX $\cdots$ dsDNA systems in $10 \mathrm{mM}$ Tris- $\mathrm{HCl}$ buffer ( $\mathrm{pH} 7.2)$ at $25^{\circ} \mathrm{C}$. 
The determination of fluorescence lifetimes was carried out to confirm that the static quenching is the sole reason for the observed fluorescence quenching. According to the performed time-resolved experiments, the fluorescence lifetimes of DOX and 4-pep-DOX were constant, regardless of the dsDNA concentration, and equal to $1.057 \pm 0.022 \mathrm{~ns}$ for DOX (the value is in good agreement with literature data [40]) and $1.076 \pm 0.006 \mathrm{~ns}$ for 4-pep-DOX. Therefore, $\tau_{0} / \tau=1$, which is characteristic for pure static quenching. This is in a good agreement with the results presented in Figure 4, since the formation of a complex is often reflected in a change of the absorption spectrum of the fluorophore.

\subsection{Isothermal Titration Calorimetry}

The ITC method was applied to determine the binding constants $\left(K_{I T C}\right)$ and the thermodynamic parameters $\left(\Delta G_{I T C}, \Delta H_{I T C}, \Delta S_{I T C}\right)$ for the interactions of DOX and 4-pep-DOX with dsDNA. Representative binding isotherms for the interactions under study are shown in Figure 9, and the thermodynamic parameters are summarized in Table 1 . The molar ratios of the resulting complexes were estimated based on ITC data and they are $7.29( \pm 0.09)$ and $7.98( \pm 1.23)$ for DOX to dsDNA and 4-pep-DOX to dsDNA, respectively. The binding constants of the resulting complexes, as well as the binding enthalpies, were obtained directly from the calorimetric experiments by fitting binding isotherms (a nonlinear least-squares procedure) to a model that assumes a single set of identical binding sites.
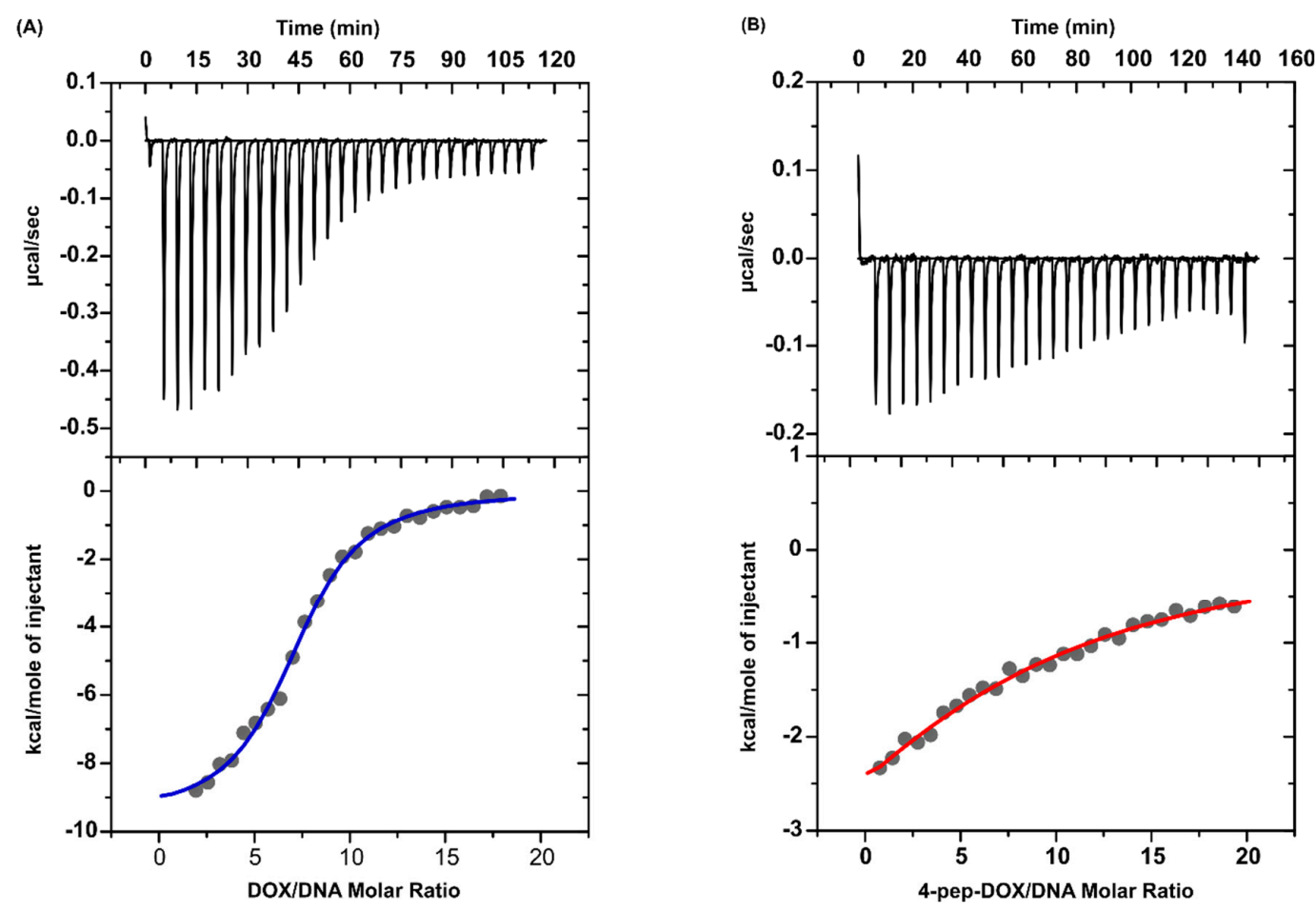

Figure 9. Calorimetric titration isotherms of the binding interaction between (A) DOX and dsDNA and between (B) 4-pep-DOX and dsDNA in $10 \mathrm{mM}$ Tris-HCl buffer (pH 7.2, $25^{\circ} \mathrm{C}$ ).

Table 1. Thermodynamic parameters of DOX and 4-pep-DOX bound to dsDNA in $10 \mathrm{mM}$ Tris- $\mathrm{HCl}$ buffer ( $\mathrm{pH} 7.2$ ) at $25^{\circ} \mathrm{C}$ (standard deviation values in parentheses). ITC, isothermal titration calorimetry.

\begin{tabular}{ccc}
\hline Parameter & DOX $\cdots$ dsDNA & 4-pep-DOX $\cdots$ dsDNA \\
\hline $\log K_{I T C}$ & $6.03( \pm 0.04)$ & $4.24( \pm 0.09)$ \\
$\Delta H_{I T C}[\mathrm{kcal} / \mathrm{mol}]$ & $-9.52( \pm 0.17)$ & $-5.84( \pm 1.27)$ \\
$\mathrm{T} \Delta S_{I T C}[\mathrm{kcal} / \mathrm{mol}]$ & -1.3 & -0.05 \\
$\Delta G_{I T C}[\mathrm{kcal} / \mathrm{mol}]$ & $-8.26( \pm 0.05)$ & $-5.78( \pm 0.12)$ \\
\hline
\end{tabular}


The standard thermodynamic relationships, namely $\Delta G_{I T C}=-R T \ln K_{I T C}=\Delta H_{I T C}-\mathrm{T} \Delta S_{\text {ITC }}$, were used to calculate the free energy of binding $\left(\Delta G_{\text {ITC }}\right)$ and the entropy change $\left(T \Delta S_{\text {ITC }}\right)$. The formation of the investigated dsDNA complexes is an enthalpy-driven process (Table 1). The negative values of the binding enthalpy and small entropic contribution correspond to the intercalative nature of the tetracyclic core of the low-molecular ligands. The modification of the DOX structure with a Leu-Ala-Gly-Gly tetrapeptide results in a decreasing strength of interaction. This phenomenon is reflected in the values of the binding constant $\log K_{\text {ITC }}$ (DOX-dsDNA) $>\log K_{I T C}$ (4-pep-DOX-dsDNA) and remains in agreement with the results obtained from the spectroscopic measurements. In contrast to DOX, the presence of the hydrophobic peptide chain in the structure of 4-pep-DOX hinders the intercalating interactions of the modified ligand with dsDNA, and weakens its ability to form hydrogen-bonding and electrostatic interactions, which are typical for groove binders [41]. According to the general rule, the more new bonds are formed and the stronger they are, the more energy (heat) is released. Thus, the difference in the binding enthalpy results from the different mode of the DOX-dsDNA and 4-pep-DOX-dsDNA interactions. This phenomenon probably is the most important factor responsible for the release of a larger amount of energy in the case of DOX binding to dsDNA.

\subsection{Molecular Dynamics Simulations}

To provide a molecular-level understanding of the differences in the stability of the intercalation complexes formed by DOX and 4-pep-DOX with dsDNA, we computed the free energy profiles for the two different intercalation modes in which the amino sugar moiety is extended into either the minor or major groove. As a collective coordinate describing the intercalation process, we used the separation distance between the centers of mass of the two base pairs forming the intercalation site and the planar chromophore of DOX and 4-pep-DOX (see Figure 10A).
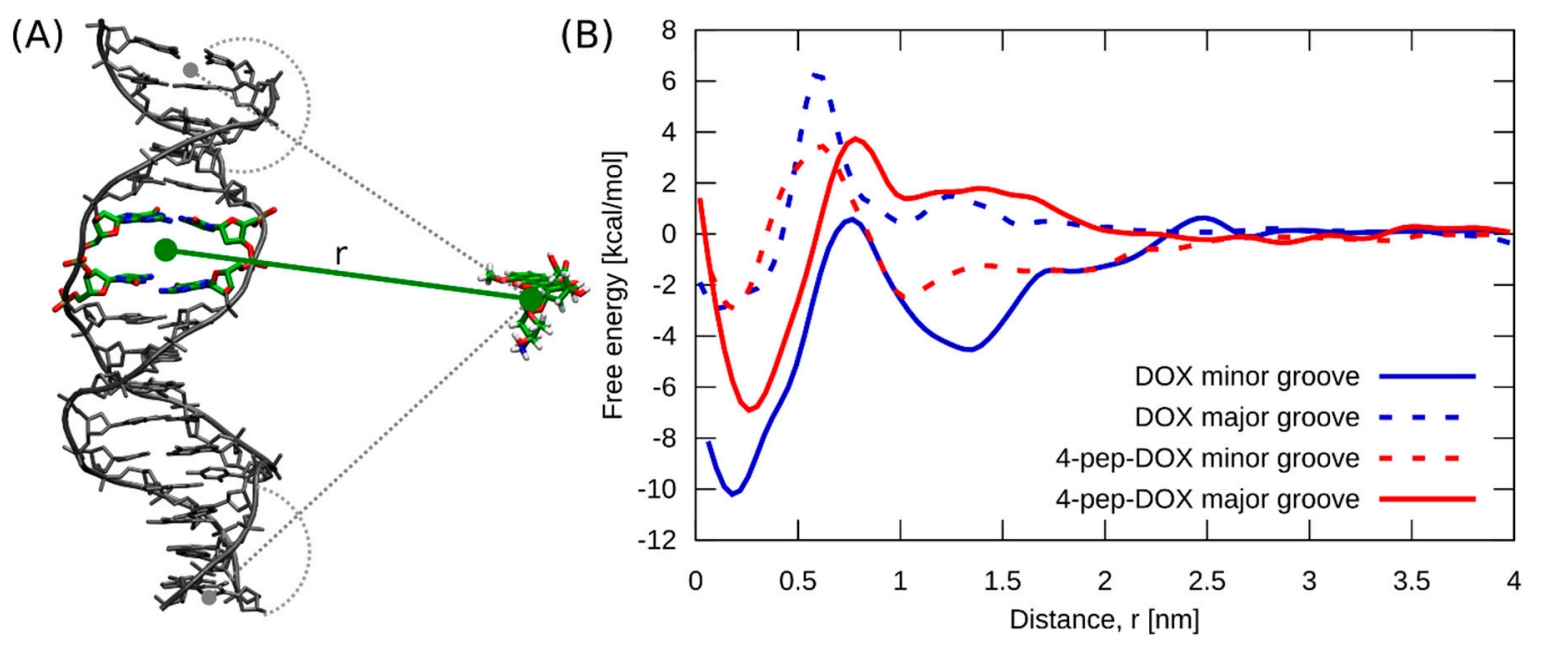

Figure 10. (A) Intercalation of DOX and 4-pep-DOX into dsDNA in the simulation was studied using the coordinate defined as the separation distance between the centers of mass of the two base pairs forming the intercalation site, and the planar chromophore of the ligand (green solid line). In addition, one-sided harmonic potentials were used to prevent association of the ligands at the dsDNA ends (see Methods section, grey dashed lines.) (B) Free energy profiles for the formation of the intercalation complexes of DOX and 4-pep-DOX with dsDNA as a function of the separation distance between them (r), in two intercalation modes (minor/major groove).

Comparison of the two free energy profiles obtained for the DOX $\cdots$ dsDNA system (blue lines in Figure 10B) strongly suggests that the highly stable DOX intercalation complex, observed in spectrophotometric titrations and ITC, corresponds to the minor-groove binding mode. Indeed, the intercalation of DOX from the major-groove side is $7.5 \mathrm{kcal} / \mathrm{mol}$ less favorable. This conclusion is further supported by a very good agreement between the depth of the main free energy minimum 
computed for DOX intercalating from the minor groove $(-9.8 \mathrm{kcal} / \mathrm{mol}$ at $\sim 0.2 \mathrm{~nm})$ and the measured binding free energies. The free energy simulations further revealed that the intercalation of DOX is preceded by its relatively strong binding to the dsDNA surface $(-4.5 \mathrm{kcal} / \mathrm{mol})$ with a clear kinetic barrier to overcome. In contrast, 4-pep-DOX (red lines in Figure 10B) shows a $3.7 \mathrm{kcal} / \mathrm{mol}$ preference for intercalation from the major groove. The predicted absolute binding free energy in this case $(-6.7 \mathrm{kcal} / \mathrm{mol})$ is consistent with our ITC results and, to a lesser extent, the spectrophotometric values, supporting the conclusion that the stable intercalation complexes of 4-pep-DOX observed in our experiments are in fact characterized by the major-groove binding mode.

To structurally compare the four intercalation complexes considered in Figure 10B, we performed a cluster analysis of the MD-generated unbiased ensembles. This was done using the hybrid k-centers k-medoids clustering algorithm for all heavy atoms of DOX and 4-pep-DOX, with a root mean square deviation (RMSD) cut-off of $0.3 \mathrm{~nm}$. Before clustering, the structures were superimposed by minimizing a heavy-atom RMSD for the two dsDNA base pairs forming the intercalation site [42].

Figure 11 shows, separately, the most likely structures of DOX $\cdots$ dsDNA and 4-pep-DOX $\cdots$ dsDNA complexes identified by our cluster analysis for each of the four intercalation cases considered. As expected, the energetically most favorable DOX $\cdots$ dsDNA complex in the minor-groove mode is characterized by a well-defined structure with one preferred arrangement of the ligand with respect to the dsDNA duplex ( $85 \%$ of the bound ensemble). This is also manifested by the limited structural fluctuations of the ligand within the intercalation site, and by strong interactions between the positively charged amino group of DOX with dsDNA phosphate groups, with the mean distance to the closest phosphate being $0.62 \mathrm{~nm}$. By comparison, intercalation of DOX from the major-groove side does not allow for a favorable electrostatic contact between the amino group and the dsDNA backbone (the mean distance to the closest phosphate is $1.06 \mathrm{~nm}$ ), resulting in a substantially reduced stability of the complex.

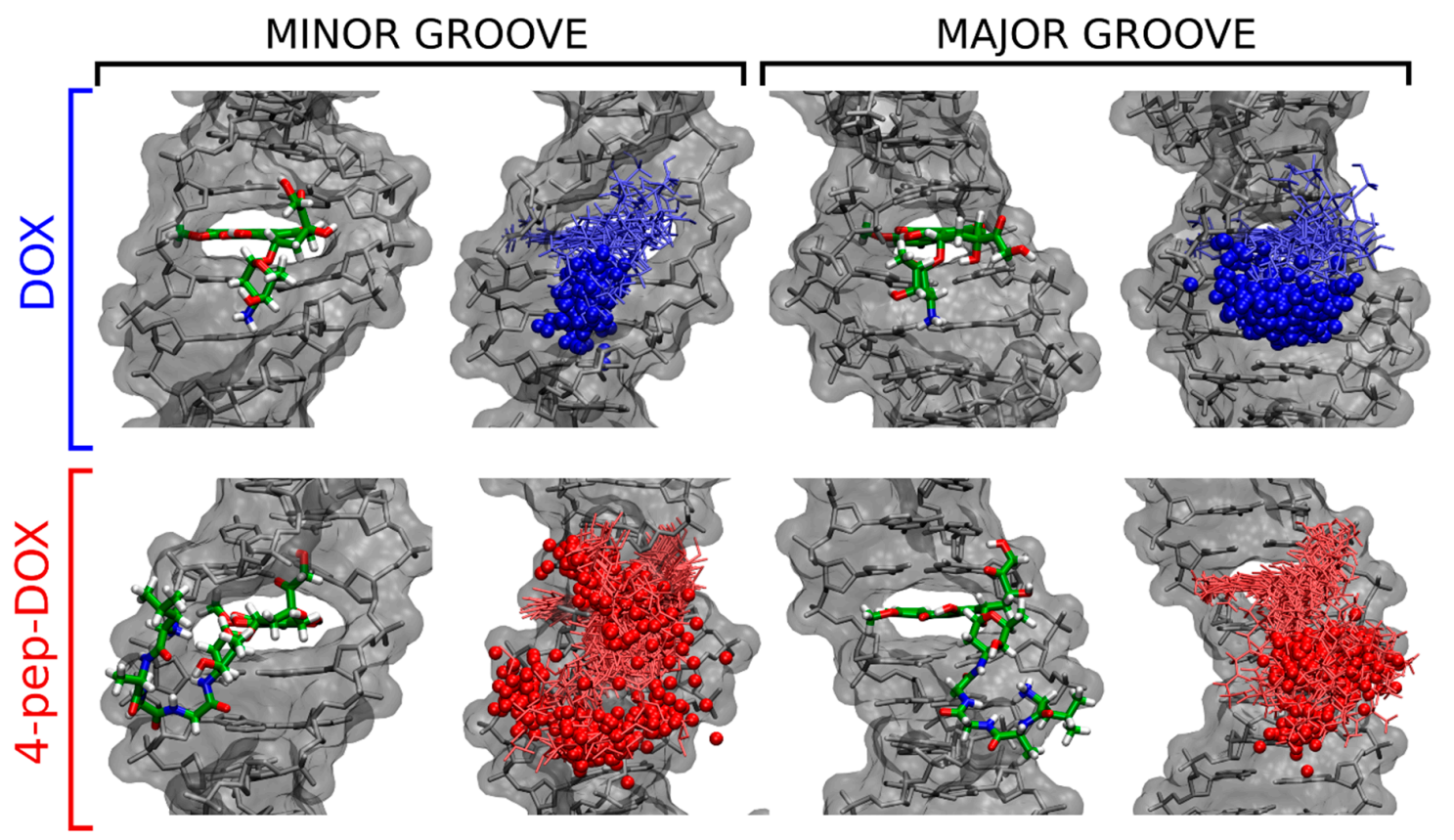

Figure 11. The most likely structures (left) and the range of ligand fluctuations (right) in the two considered intercalation modes (minor/major groove) of the DOX $\cdots$ dsDNA and 4-pep-DOX $\cdots$ dsDNA complexes. In addition, 100 overlaid representative positions of the protonated amino group (in the amino sugar of DOX or at the N-terminus of the tetrapeptide of 4-pep-DOX) are marked with spheres.

In contrast to the DOX case, the most likely arrangement of 4-pep-DOX intercalated into dsDNA from the minor groove accounts for only $35 \%$ of the ensemble (Figure 11). In this position, 
the tetrapeptide fragment resides outside the minor groove, not interacting specifically with the dsDNA chain despite a relatively small average distance to the closest phosphate group $(0.76 \mathrm{~nm})$. Notably, DOX and 4-pep-DOX intercalated via the minor groove differ substantially in the orientation of their planar chromophore relative to the flanking base pairs. In particular, the 4-pep-DOX core is rotated by $33^{\circ}$ resulting in a decreased stacking overlap with the flanking nucleobases, as compared to DOX (see Figure S3, Supplementary Materials).

In its more stable major-groove intercalation mode, 4-pep-DOX exhibits one well-defined structure ( $74 \%$ of the ensemble, Figure 11), in which the tetrapeptide interacts largely with one dsDNA strand, with the mean distance of the amino group to the closest phosphate equal to $0.45 \mathrm{~nm}$. This suggests that effective stabilization of the intercalation complex requires accommodation of the flexible peptide substituent in the wider and more accessible major groove.

\section{Materials and Methods}

\subsection{Materials}

Fmoc-Leu-Ala-Gly-Gly and Fmoc-Gly-Pro-Leu-Gly-Leu-Ala-Gly-Gly peptides were purchased from Lipopharm.pl (Zblewo, Poland). Oligonucleotides 5'-CGT ACG CGT ACG CGT ACG CG-3' and 5'-CGC GTA CGC GTA CGC GTA CG-3' were purchased from Future Synthesis (Poznan, Poland). Collagenase IV and Hank's Balanced Salt Solution (HBSS), with calcium and magnesium, were purchased from ThermoFisher Scientific (Walthman, MA, USA). Acetonitrile (ACN), 4-aminophenylmercuric acetate (APMA), dichloromethane (DCM), 2,5-dihydroxybenzoic acid (DHB), $\mathrm{N}, \mathrm{N}$-dimethylformamide (DMF), doxorubicin hydrochloride, formic acid, isobutyl chloroformate, methanol, sodium hydroxide, tetrahydrofuran (THF), triethylamine (TEA), and Tris- $\mathrm{HCl}$ were purchased from Sigma-Aldrich (St. Louis, MO, USA). Column chromatography was performed using silica gel NORMASIL 60 (40-63 mesh, VWR Chemicals, Radnor, PA, USA). Thin-layer chromatography was performed using silica plates, 60G, $\mathrm{F}_{254}$ (Sigma-Aldrich, St. Louis, MO, USA).

\subsection{Methods}

\subsubsection{Assembly of dsDNA}

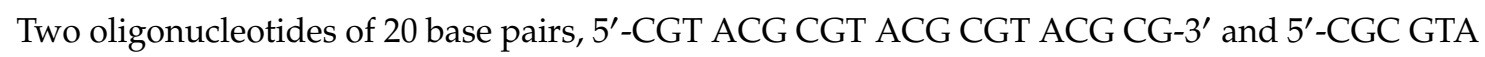
CGC GTA CGC GTA CG-3', were mixed at concentrations of $10 \mu \mathrm{M}$ each, in $10 \mathrm{mM}$ Tris-HCl buffer (pH 7.2). The mixtures were submitted to the annealing procedure at $95^{\circ} \mathrm{C}$ for $5 \mathrm{~min}, 50^{\circ} \mathrm{C}$ for $30 \mathrm{~min}$, and cooled to $4{ }^{\circ} \mathrm{C}$ in 20 min using a Mastercycler gradient from Eppendorf (Hamburg, Germany). The formation of double-stranded DNA was confirmed by the HPLC Dionex Ultimate 3000 System (Waltham, MA, USA; data not shown). The analysis was performed on the XBridge OST C18 column $\left(2.5 \mu \mathrm{m}, 4.6 \times 50 \mathrm{~mm}\right.$; Waters, Milford, MA, USA) at $20^{\circ} \mathrm{C}$. The flow was set at $1 \mathrm{~mL} / \mathrm{min}$ with a mobile phase consisting of solvent $\mathrm{A}(1 \% \mathrm{ACN}$ with $50 \mathrm{mM}$ triethylamine acetate) and solvent $\mathrm{B}(80 \% \mathrm{ACN})$. The gradient was $0-20 \%$ of solvent $\mathrm{B}$ in $20 \mathrm{~min}$.

\subsubsection{Enzymatic Cleavage of Peptide by MMPs}

The MMP-2/-9-cleavable octapeptide Fmoc-Gly-Pro-Leu-Gly-Leu-Ala-Gly-Gly was evaluated by enzymatic digestion with the use of collagenase IV (containing MMP-2/-9). In the first step, $1 \mathrm{~mL}$ of HBSS was added to $1 \mathrm{~g}$ of collagenase IV $(205 \mathrm{u} / \mathrm{mg})$ and mixed to complete dissolution. Activation of collagenase IV was performed using $1 \mathrm{mM}$ APMA in $0.15 \mathrm{M} \mathrm{NaOH}$ for $1.5 \mathrm{~h}$ at $37^{\circ} \mathrm{C}[24,43]$. The octapeptide stock solution was added to activated $1 \mathrm{mM}$ collagenase IV and incubated at $37^{\circ} \mathrm{C}$. The aliquots were removed and analyzed by HPLC, between 2 and $12 \mathrm{~h}$. The HPLC Dionex Ultimate 3000 (Waltham, MA, USA) was equipped with a bioZen Intact XB-C8 column $(3.6 \mu \mathrm{m}, 2.1 \times 150 \mathrm{~mm}$; Phenomenex, Aschaffenburg, Germany). The flow rate was set at $0.5 \mathrm{~mL} / \mathrm{min}$ with a mobile phase consisting of solvent A $(0.1 \%$ TFA) and solvent B $(100 \%$ ACN). The gradient was as follows: $0-5$ min, 
$0 \%$ of solvent $\mathrm{B} ; 5-8 \mathrm{~min}, 0-30 \%$ of solvent $\mathrm{B}$. The hydrolysis product was detected by MALDI TOF/TOF 5800 mass spectrometry (AB Sciex, Darmstadt, Germany).

\subsubsection{Synthesis of Fmoc-Leu-Ala-Gly-Gly-DOX}

Isobutyl chloroformate $(9.6 \mu \mathrm{L}, 74.3 \mu \mathrm{mol})$ and TEA $(10.4 \mu \mathrm{L}, 74.3 \mu \mathrm{mol})$ were added to the solution of Fmoc-Leu-Ala-Gly-Gly $(40 \mathrm{mg}, 74.3 \mu \mathrm{mol})$ in DMF $(1 \mathrm{~mL})$ cooled to $-10^{\circ} \mathrm{C}$. After $20 \mathrm{~min}$ of vigorous stirring, a solution of DOX (obtained by treating DOX hydrochloride ( $43 \mathrm{mg}, 74.3 \mu \mathrm{mol}$ ) in DMF with TEA $(10.4 \mu \mathrm{L}, 74.3 \mu \mathrm{mol}))$ in DMF $(0.5 \mathrm{~mL})$ was added to the reaction mixture. After $1 \mathrm{~h}$ at RT, DMF was evaporated, azeotropically, with toluene on a rotary evaporator (Heidolph Hei-VAP Gold 3, Heidolph, Schwabach, Germany). The raw Fmoc-Leu-Ala-Gly-Gly-DOX was purified by preparative column chromatography, using $\mathrm{CHCl3}$ : $\mathrm{MeOH}$ 30: 1 as an eluent, to give the desired product $(59 \mathrm{mg})$ in a $75 \%$ yield.

\subsubsection{Synthesis of Leu-Ala-Gly-Gly-DOX}

Morpholine $(0.5 \mathrm{~mL})$ was added to a stirred solution of Fmoc-Leu-Ala-Gly-Gly-DOX (50 mg, $47 \mu \mathrm{mol})$ in DMF $(0.5 \mathrm{~mL})$, and the stirring was carried on for a further $2 \mathrm{~h}$. Afterward, the mixture was neutralized with trifluoroacetic acid $(0.6 \mathrm{~mL})$. The raw product was isolated on a semi-preparative HPLC System (Shimadzu, LC 20AD, Shimadzu, Canby, OR, USA) using a Gemini NX Column $(5.0 \mu \mathrm{m}$, $10 \times 150 \mathrm{~mm}$ ) to give $24 \mathrm{mg}$ in a $61 \%$ yield. The flow rate was set at $4.0 \mathrm{~mL} / \mathrm{min}$ with the mobile phase consisting of solvent A ( $0.1 \%$ formic acid) and solvent B $(100 \% \mathrm{ACN})$. The gradient was as follows: $0-15 \mathrm{~min}, 10-90 \%$ of solvent $\mathrm{B} ; 15-20 \mathrm{~min}, 90 \%$ of solvent $\mathrm{B}$. The chemical structure of the product was confirmed using MALDI TOF/TOF 5800 mass spectrometry (AB Sciex, Darmstadt, Germany). As a matrix, 2,5-dihydroxybenzoic acid was used. The measurement was done in reflector positive ion mode. Samples were prepared using the dried droplet preparation method by mixing $0.8 \mathrm{~mL}$ of an analyte solution with $0.8 \mathrm{~mL}$ of the matrix solution (directly on a plate). MS spectra were acquired from 789 to $961 \mathrm{~m} / \mathrm{z}$ for a total of 1000 laser shots by a $1 \mathrm{kHz}$ OptiBeam laser (AB Sciex, Darmstadt, Germany).

\subsubsection{Spectrophotometric Titrations}

The concentrations of the studied compounds (DOX and 4-pep-DOX) were confirmed spectrophotometrically based on the absorbance and the value of the molar extinction coefficient determined at $480 \mathrm{~nm}\left(\varepsilon 480=11500 \mathrm{M}^{-1} \mathrm{~cm}^{-1}\right)$ [44]. UV-Vis spectrophotometric experiments were carried out in $10 \mathrm{mM}$ Tris-HCl buffer ( $\mathrm{pH} 7.2)$ at $25^{\circ} \mathrm{C}$ using a PerkinElmer Lambda $650 \mathrm{UV} / \mathrm{Vis}$ spectrophotometer (Walthnam, MA, USA). UV-Vis absorption spectra of DOX and 4-pep-DOX $(18.0 \mu \mathrm{M})$ were recorded in the absence and presence of increasing concentrations of dsDNA, up to $1.90 \mu \mathrm{M}$. In the performed spectrophotometric experiments, $2 \mathrm{~mL}$ of DOX and 4-pep-DOX at $18.0 \mu \mathrm{M}$ were titrated with ten $10 \mu \mathrm{L}$ aliquots of dsDNA solution at $40 \mu \mathrm{M}$.

\subsubsection{Steady-State and Time-Resolved Fluorescence Spectroscopy}

Steady-state fluorescence experiments were carried out at $25^{\circ} \mathrm{C}$ using a Cary Eclipse Varian spectrofluorometer (Agilent, St. Clara, CA, USA) equipped with a temperature controller and a $1.0 \mathrm{~cm}$ quartz multicell holder. The fluorescence emission spectra $\left(\lambda_{\mathrm{ex}}=490 \mathrm{~nm}\right)$ of DOX and 4-pep-DOX $(1.94 \mu \mathrm{M})$ were recorded from 510 to $690 \mathrm{~nm}$ in the absence and presence of increasing concentrations of dsDNA, up to $75 \mathrm{nM}$. In the performed fluorescence titration experiments, $2 \mathrm{~mL}$ of DOX and 4-pep-DOX at $1.94 \mu \mathrm{M}$ were titrated with fifteen $1 \mu \mathrm{L}$ aliquots of dsDNA solution at $10 \mu \mathrm{M}$. The intensity of the band at $594 \mathrm{~nm}$ (corresponding to the maximum emission of both, DOX and its analogue 4-pep-DOX) was used to calculate the association constants $\left(\mathrm{K}_{\mathrm{A}}\right)$ and other parameters. Time-resolved fluorescence measurements were performed with a FluoTime 300 high performance fluorescence lifetime spectrometer (PicoQuant, Berlin, Germany) at $20^{\circ} \mathrm{C}$. The excitation source was a pulsed LED of the PLS series ( $\lambda$ ex $=420 \mathrm{~nm}$ ). The fluorescence lifetimes of both DOX and 4-pep-DOX $(5 \mu \mathrm{M})$ were measured in the absence and presence of variable concentrations of dsDNA $(0.05 \mu \mathrm{M}$, 
$0.10 \mu \mathrm{M}, 0.15 \mu \mathrm{M}, 0.20 \mu \mathrm{M}$, and $0.25 \mu \mathrm{M})$. After each added portion of dsDNA, the studied solution was gently stirred, and the fluorescence lifetime was measured at the wavelength corresponding to the maximum of the fluorophore emission $\left(\lambda_{\mathrm{em}}=594 \mathrm{~nm}\right)$.

\subsubsection{Isothermal Titration Calorimetry}

All ITC experiments were performed at $25^{\circ} \mathrm{C}$ using an AutoITC isothermal titration calorimeter (MicroCal Inc. GE Healthcare, Northampton, MA, USA). The details of the measuring devices and experimental setup have been described previously [45]. The reagents (DOX, 4-pep-DOX, and dsDNA) were dissolved directly in $10 \mathrm{mM}$ Tris- $\mathrm{HCl}$ buffer solution ( $\mathrm{pH}$ 7.2). The experiment comprised injections of $10.02 \mu \mathrm{L}$ (29 injections, $2 \mu \mathrm{L}$ for the first injection only) of the buffered solution of DOX $(0.174 \mathrm{mM})$ or 4-pep-DOX $(0.470 \mathrm{mM})$ into the reaction cell, which initially contained the buffered solution of dsDNA ( $0.002 \mathrm{mM}$ or $0.005 \mathrm{mM}$, respectively). For each experiment, a blank was performed by injecting the titrant solution into the cell filled with the buffer only. This blank was subtracted from the corresponding titration to account for the heat of dilution. All solutions were degassed prior to the titration. The titrant was injected at approximately 4 min intervals to ensure that the titration peak returned to the baseline before the next injection. Each injection lasted $20 \mathrm{~s}$. To ensure a homogeneous mixing in the cell, the stirrer speed was kept constant at $300 \mathrm{rpm}$. Calibration of the AutoITC calorimeter was carried out using electrically generated heat pulses. The $\mathrm{CaCl}_{2}$-EDTA titration was performed to check the apparatus and the results ( $n$-stoichiometry, $\mathrm{K}, \Delta H$ ) were compared with those obtained for the same samples (a test kit) at MicroCal Inc./Malvern Instruments (Malvern, UK).

\subsubsection{Molecular Dynamics Simulations}

All simulated systems were built on the basis of the crystal structure of the doxorubicin-dsDNA complex (PDB id 1D12) [46]. Initial coordinates of a 20-bp long dsDNA helix with 5'-CGT ACG CGT ACG CGT ACG CG-3' sequence were generated by removing the two base pairs at the $3^{\prime}$-end of dsDNA in the crystal structure, and then the appropriate extension of the structure at the $5^{\prime}$ and $3^{\prime}$ ends by using the X3DNA program [47]. The obtained dsDNA-drug complexes were solvated with 13,947 TIP3P water molecules in a dodecahedral box with a cell vector length of $8.5 \mathrm{~nm}$, at physiological ionic strength $(150 \mathrm{mM} \mathrm{NaCl})$ [48]. The Amber parmbsc1 force field was used for dsDNA and ions [49]. The force field parameters for DOX and the tetrapeptide fragment of 4-pep-DOX were taken from the General Amber Force Field (GAFF) and directly from Amber, respectively [50]. Partial charges for both ligands were obtained from HF calculations in Gaussian via Merz-Kollman ESP fitting, using the 6-31G* basis set [51]. The MD simulations were performed using Gromacs 5.0.4 in the NPT ensemble, with the temperature kept at $25^{\circ} \mathrm{C}$ and using the v-rescale thermostat with the pressure kept at 1 bar using a Parrinello-Rahman barostat [52-54]. Periodic boundary conditions were applied in 3D, and the electrostatic interactions were calculated using the particle mesh Ewald (PME) method with a real-space cut-off of $1.2 \mathrm{~nm}$ and a Fourier grid spacing of $0.12 \mathrm{~nm}$ [55]. A cut-off of $1.2 \mathrm{~nm}$ was used for Lennard-Jones interactions. All bond lengths were constrained using P-LINCS for dsDNA and SETTLE for water $[56,57]$. The equations of motion were integrated using the leap-frog algorithm with a 2 fs time step.

To study the relative stability of the complexes formed by DOX and 4-pep-DOX with dsDNA duplex in two different intercalation modes (with the amino sugar extending into either the minor or major groove), we calculated the corresponding free energy profiles using replica-exchange umbrella sampling (REUS). The calculations were carried out using the PLUMED 2.0 plugin coupled to Gromacs [58]. To generate the initial configurations for the REUS simulations, we first performed short equilibrium simulations (150 ns) of the DOX and 4-pep-DOX, initially intercalated at a CpG step of dsDNA, in either a minor- or major-groove mode. In the former case, the initial configuration of the DOX $\cdots$ dsDNA intercalation complex was taken directly from the crystal structure and the 4-pep-DOX $\cdots$ dsDNA complex was then obtained by attaching the tetrapeptide moiety to the amino group of DOX. In the latter case, the orientation of both intercalators was manually inverted within the 
same intercalation site. To obtain the dissociated states for the so-prepared four systems, we ran steered MD (SMD) simulations, in which the ligands were pulled away from dsDNA during $100 \mathrm{~ns}$ using a moving harmonic potential with a force constant of $286.1 \mathrm{kcal} /\left(\mathrm{mol} \cdot \mathrm{nm}^{2}\right)$ applied to the coordinate, defined as the separation distance between the centers of mass of the two base pairs forming the intercalation site and the planar chromophore of DOX and 4-pep-DOX ( $\mathrm{r}$ vector in Figure 10A).

Next, from SMD trajectories, we generated 21 uniformly distributed $0.2 \mathrm{~nm}$ separated REUS windows. In each of these windows, the systems were simulated for $0.5 \mu$ s using the harmonic potential with a force constant of $143.05 \mathrm{kcal} /\left(\mathrm{mol} \cdot \mathrm{nm}^{2}\right)$ to restrain the system along the reaction coordinate r. In addition, we used one-sided harmonic potentials with a force constant of $286.1 \mathrm{kcal} /\left(\mathrm{mol} \cdot \mathrm{nm}^{2}\right)$, turning on below $1.2 \mathrm{~nm}$ to prevent ligands binding at the dsDNA ends (grey dashed lines in Figure 10A). The exchanges between neighboring windows were attempted every 2 ps, and the acceptance rate turned out to be $19 \%$. The free energy profiles were determined from the last $450 \mathrm{~ns}$ of the thus obtained trajectories using the standard weighted histogram analysis method [59]. All molecular images were created using VMD 1.9.2 (Univerisity of Illinois, Urbana, IL, USA) [60].

\section{Conclusions}

In this work, we successfully synthesized the tetrapeptide-DOX (4-pep-DOX) adduct as a product of octapeptide cleavage by MMPs, for extensive investigation of the parameters that are critical in forming a 4-pep-DOX $\cdots$ dsDNA complex. The experimental and theoretical studies demonstrated that the presence of tetrapeptide does not affect the overall tendency of DOX to intercalate into dsDNA, but rather changes its binding mode. While the main mode of action of DOX has been attributed to its intercalation from the minor groove of dsDNA, the binding of 4-pep-DOX primarily occurs from the major groove. Multifaceted binding modes for DOX and 4-pep-DOX highlight the important role of electrostatic and hydrophobic interactions between the negatively charged phosphate group on the groove surface and the peptide chain of 4-pep-DOX. Hence, these results demonstrate that the release of a free DOX from the MMP-cleaved intermediate product by intracellular non-specific proteases is probably not vital to the cytostatic action of the drug. We believe that the presented detailed explanation of the intercalation mechanism of 4-pep-DOX adduct can be useful for paving the way for the future design of peptide-DOX prodrugs.

Supplementary Materials: Supplementary materials can be found at http://www.mdpi.com/1422-0067/21/18/ 6923/s1.

Author Contributions: Conceptualization, K.B., J.R. and J.P.; Formal Analysis, K.B., K.Ż., M.K., W.K., D.W., W.W., J.R., J.C. and J.P.; Investigation, K.B., K.Ż., M.K., W.K. and D.W.; Funding acquisition, J.R. and J.P.; Writing—original draft, K.B., K.Ż., M.K., W.K. and D.W.; Writing-review and editing, J.R., J.C. and J.P.; Supervision, J.R. and J.P.; Project administration, K.B. All authors have read and agreed to the published version of the manuscript.

Funding: This work was supported by the Polish Ministry of Science and Higher Education under Grant Nos. DS 531-T080-D494-20 (J.R.) and DS 531-M045-D788-19 (J.P.). This research was supported in part by PL-Grid Infrastructure.

Acknowledgments: We wish to thank the Academic Computer Centre in Gdańsk, Poland, for granting CPU time. This research was supported in part by PL-Grid Infrastructure.

Conflicts of Interest: The authors declare no conflict of interest.

\section{Abbreviations}

$\begin{array}{ll}\text { DOX } & \text { Doxorubicin } \\ \text { MMPs } & \text { Matrix metalloproteinases } \\ \text { MD } & \text { Molecular dynamics } \\ \text { ITC } & \text { Isothermal titration calorimetry }\end{array}$




\section{References}

1. Bray, F.; Ferlay, J.; Soerjomataram, I.; Siegel, R.L.; Torre, L.A.; Jemal, A. Global cancer statistics 2018: GLOBOCAN estimates of incidence and mortality worldwide for 36 cancers in 185 countries. CA Cancer J. Clin. 2018, 68, 394-424. [CrossRef] [PubMed]

2. Tavan, H.; Azadi, A.; Veisani, Y. Return to work in cancer patients: A systematic review and meta-analysis. Indian J. Palliat. Care 2019, 25, 147-152. [PubMed]

3. Gewirtz, D.A. A critical evaluation of the mechanisms of action proposed for the antitumor effects of the anthracycline antibiotics adriamycin and daunorubicin. Biochem. Pharm. 1999, 57, 727-741. [CrossRef]

4. Petrioli, R.; Fiaschi, A.I.; Francini, E.; Pascucci, A.; Francini, G. The role of doxorubicin and epirubicin in the treatment of patients with metastatic hormone-refractory prostate cancer. Cancer Treat. Rev. 2008, 34, 710-718. [CrossRef] [PubMed]

5. Arcamone, F. Doxorubicin: Anticancer Antibiotics; Academic Press: New York, NY, USA, 1981.

6. Minotti, G.; Menna, P.; Salvatorelli, E.; Cairo, G.; Gianni, L. Anthracyclines: Molecular advances and pharmacology developments in antitumor activity and cardiotoxicity. Pharm. Rev. 2004, 56, 185-229. [CrossRef] [PubMed]

7. Binaschi, M.; Capranico, G.; Dal Bo, L.; Zunino, F. Relationship between lethal effects and topoisomerase II-mediated double-stranded DNA breaks produced by anthracyclines with different sequence specificity. Mol. Pharm. 1997, 51, 1053-1059. [CrossRef]

8. Feinstein, E.; Canaani, E.; Weiner, L.M. Dependence of nucleic acid degradation on in situ free-radical production by adriamycin. Biochemistry 1993, 32, 13156-13161. [CrossRef]

9. Tewey, K.M.; Rowe, T.C.; Yang, L.; Halligan, B.D.; Liu, L.F. Adriamycin-induced DNA damage mediated by mammalian DNA topoisomerase II. Science 1984, 226, 466-468. [CrossRef]

10. Cutts, S.M.; Parsons, P.G.; Sturm, R.A.; Phillips, D.R. Adriamycin-induced DNA adducts inhibit the DNA interactions of transcription factors and RNA polymerase. J. Biol. Chem. 1996, 271, 5422-5429. [CrossRef]

11. Swain, S.M.; Whaley, F.S.; Ewer, M.S. Congestive heart failure in patients treated with doxorubicin: A retrospective analysis of three trials. Cancer 2003, 97, 2869-2879. [CrossRef]

12. Bally, M.B.; Nayar, R.; Masin, D.; Cullis, P.R.; Mayer, L.D. Studies on the myelosuppressive activity of doxorubicin entrapped in liposomes. Cancer Chemother. Pharm. 1990, 27, 13-19. [CrossRef] [PubMed]

13. Carvalho, C.; Santos, R.; Cardoso, S.; Correia, S.; Oliveira, P.; Santos, M.; Moreira, P. Doxorubicin: The good, the bad and the ugly effect. Curr. Med. Chem. 2009, 16, 3267-3285. [CrossRef] [PubMed]

14. Kalepu, S.; Nekkanti, V. Insoluble drug delivery strategies: Review of recent advances and business prospects. Acta Pharm. Sin. B 2015, 5, 442-453. [CrossRef] [PubMed]

15. Singh, S.K.; Singh, S.; Wlillard, J.; Singh, R. Drug delivery approaches for breast cancer. Int. J. Nanomed. 2017, 12, 6205-6218. [CrossRef] [PubMed]

16. Rudra, A.; Li, J.; Shakur, R.; Bhagchandani, S.; Langer, R. Trends in therapeutic conjugates: Bench to clinic. Bioconjug. Chem. 2020, 31, 462-473. [CrossRef]

17. Janssen, M.; Mihov, G.; Welting, T.; Thies, J.; Emans, P. Drugs and polymers for delivery systems in OA joints: Clinical needs and opportunities. Polymers 2014, 6, 799-819. [CrossRef]

18. Milton Harris, J.; Chess, R.B. Effect of pegylation on pharmaceuticals. Nat. Rev. Drug Discov. 2003, 2, $214-221$. [CrossRef]

19. Yoo, H.S.; Park, T.G. Biodegradable polymeric micelles composed of doxorubicin conjugated PLGA-PEG block copolymer. J. Control. Release 2001, 70, 63-70. [CrossRef]

20. Maeda, H.; Khatami, M. Analyses of repeated failures in cancer therapy for solid tumors: Poor tumor-selective drug delivery, low therapeutic efficacy and unsustainable costs. Clin. Transl. Med. 2018, 7, 1-20. [CrossRef]

21. Cathcart, J.; Pulkoski-Gross, A.; Cao, J. Targeting matrix metalloproteinases in cancer: Bringing new life to old ideas. Genes Dis. 2015, 2, 26-34. [CrossRef]

22. Vihinen, P.; Kähäri, V.M. Matrix metalloproteinases in cancer: Prognostic markers and therapeutic targets. Int. J. Cancer 2002, 99, 157-166. [CrossRef] [PubMed]

23. Egeblad, M.; Werb, Z. New functions for the matrix metalloproteinases in cancer progression. Nat. Rev. Cancer 2002, 2, 161-174. [CrossRef] [PubMed]

24. You, Y.; Xu, Z.; Chen, Y. Doxorubicin conjugated with a trastuzumab epitope and an MMP-2 sensitive peptide linker for the treatment of HER2-positive breast cancer. Drug Deliv. 2018, 25, 448-460. [CrossRef] [PubMed] 
25. Zhu, L.; Wang, T.; Perche, F.; Taigind, A.; Torchilin, V.P. Enhanced anticancer activity of nanopreparation containing an MMP2-sensitive PEG-drug conjugate and cell-penetrating moiety. Proc. Natl. Acad. Sci. USA 2013, 110, 17047-17052. [CrossRef]

26. Zhang, J.; Yuan, Z.F.; Wang, Y.; Chen, W.H.; Luo, G.F.; Cheng, S.X.; Zhuo, R.X.; Zhang, X.Z. Multifunctional envelope-type mesoporous silica nanoparticles for tumor-triggered targeting drug delivery. J. Am. Chem. Soc. 2013, 135, 5068-5073. [CrossRef]

27. Bacinello, D.; Garanger, E.; Taton, D.; Tam, K.C.; Lecommandoux, S. Enzyme-degradable self-assembled nanostructures from polymer-peptide hybrids. Biomacromolecules 2014, 15, 1882-1888. [CrossRef]

28. Lee, G.Y.; Park, K.; Kim, S.Y.; Byun, Y. MMPs-specific PEGylated peptide-DOX conjugate micelles that can contain free doxorubicin. Eur. J. Pharm. Biopharm. 2007, 67, 646-654. [CrossRef]

29. Kratz, F.; Müller, I.A.; Ryppa, C.; Warnecke, A. Prodrug strategies in anticancer chemotherapy. ChemMedChem 2008, 3, 20-53. [CrossRef]

30. Mansour, A.M.; Drevs, J.; Esser, N.; Hamada, F.M.; Badary, O.A.; Unger, C.; Fichtner, I.; Kratz, F. A new approach for the treatment of malignant melanoma: Enhanced antitumor efficacy of an albumin-binding doxorubicin prodrug that is cleaved by matrix metalloproteinase 2. Cancer Res. 2003, 63, 4062-4066.

31. Guarnieri, D.; Biondi, M.; Yu, H.; Belli, V.; Falanga, A.P.; Cantisani, M.; Galdiero, S.; Netti, P.A. Tumor-activated prodrug (TAP)-conjugated nanoparticles with cleavable domains for safe doxorubicin delivery. Biotechnol. Bioeng. 2015, 112, 601-611. [CrossRef]

32. Jiang, T.; Olson, E.S.; Nguyen, Q.T.; Roy, M.; Jennings, P.A.; Tsien, R.Y. Tumor imaging by means of proteolytic activation of cell-penetrating peptides. Proc. Natl. Acad. Sci. USA 2004, 101, 17867-17872. [CrossRef] [PubMed]

33. Wang, H.X.; Yang, X.Z.; Sun, C.Y.; Mao, C.Q.; Zhu, Y.H.; Wang, J. Matrix metalloproteinase 2-responsive micelle for siRNA delivery. Biomaterials 2014, 35, 7622-7634. [CrossRef] [PubMed]

34. Ralhan, K.; KrishnaKumar, V.G.; Gupta, S. Piperazine and DBU: A safer alternative for rapid and efficient Fmoc deprotection in solid phase peptide synthesis. RSC Adv. 2015, 5, 104417-104425. [CrossRef]

35. Fields, G.B. Methods for removing the Fmoc group. Methods Mol. Biol. 1994, 35, 17-27. [PubMed]

36. Eftink, M.R.; Ghiron, C.A. Fluorescence quenching studies with proteins. Anal. Biochem. 1981, 114, $199-227$. [CrossRef]

37. Ware, W.R. Oxygen quenching of fluorescence in solution: An experimental study of the diffusion process. J. Phys. Chem. 1962, 66, 455-458. [CrossRef]

38. Xiang, G.; Tong, C.; Lin, H. Nitroaniline isomers interaction with bovine serum albumin and toxicological implications. J. Fluoresc. 2007, 17, 512-521. [CrossRef]

39. Congdon, R.W.; Muth, G.W.; Splittgerber, A.G. The binding interaction of coomassie blue with proteins. Anal. Biochem. 1993, 213, 407-413. [CrossRef]

40. Dai, X.; Yue, Z.; Eccleston, M.E.; Swartling, J.; Slater, N.K.H.; Kaminski, C.F. Fluorescence intensity and lifetime imaging of free and micellar-encapsulated doxorubicin in living cells. Nanomed. Nanotechnol. Biol. Med. 2008, 4, 49-56. [CrossRef]

41. Chaires, J.B. A thermodynamic signature for drug-DNA binding mode. Arch. Biochem. Biophys. 2006, 453, 26-31. [CrossRef]

42. Beauchamp, K.A.; Bowman, G.R.; Lane, T.J.; Maibaum, L.; Haque, I.S.; Pande, V.S. MSMBuilder2: Modelling conformational dynamics on the picosecond to millisecond scale. J. Chem. Theory Comput. 2011, 7, 3412-3419. [CrossRef] [PubMed]

43. Shi, N.Q.; Gao, W.; Xiang, B.; Qi, X.R. Enhancing cellular uptake of activable cell-penetrating peptide-doxorubicin conjugate by enzymatic cleavage. Int. J. Nanomed. 2012, 7, 1613-1621.

44. Munnier, E.; Cohen-Jonathan, S.; Linassier, C.; Douziech-Eyrolles, L.; Marchais, H.; Soucé, M.; Hervé, K.; Dubois, P.; Chourpa, I. Novel method of doxorubicin-SPION reversible association for magnetic drug targeting. Int. J. Pharm. 2008, 363, 170-176. [CrossRef] [PubMed]

45. Panuszko, A.; Bruździak, P.; Zielkiewicz, J.; Wyrzykowski, D.; Stangret, J. Effects of urea and trimethylamine-N-oxide on the properties of water and the secondary structure of hen egg white lysozyme. J. Phys. Chem. B 2009, 113, 14797-14809. [CrossRef] [PubMed]

46. Frederick, C.A.; Dean Williams, L.; Ughetto, G.; van der Marel, G.A.; van Boom, H.-J.; Rich, A.; Wang, A.H.-J. Structural comparison of anticancer drug-DNA complexes: Adriamycin and daunomycin. Biochemisty 1990, 29, 2538-2549. [CrossRef] 
47. Lu, X.-J.; Olson, W.K. 3DNA: A software package for the analysis, rebuilding and visualisation of three-dimensional nucleic acid structures. Nucl. Acids Res. 2003, 31, 5108-5121. [CrossRef] [PubMed]

48. Jorgensen, W.L.; Chandrasekhar, J.; Madura, J.D.; Impey, R.W.; Klein, M.L. Comparison of simple potential functions for simulating liquid water. J. Chem. Phys. 1983, 79, 926-935. [CrossRef]

49. Ivani, I.; Dans, P.D.; Noy, A.; Pérez, A.; Faustino, I.; Hospital, A.; Walther, J.; Andrio, P.; Goñi, R.; Balaceanu, A.; et al. Parmbsc1: A refined force field for DNA simulations. Nat. Methods 2015, 13, 55-58. [CrossRef]

50. Wang, J.; Wang, W.; Kollman, P.A.; Case, D.A. Automatic atom type and bond type perception in molecular mechanical calculations. J. Mol. Graph. Model. 2006, 25, 247-260. [CrossRef]

51. Frisch, M.J.; Trucks, G.W.; Schlegel, H.B.; Scuseria, G.E.; Robb, M.A.; Cheeseman, J.R.; Scalmani, G.; Barone, V.; Petersson, G.A.; Nakatsuji, H.; et al. Gaussian 09; Software for Calculation; Gaussian, Inc.: Wallingford, CT, USA, 2016.

52. Hess, B.; Kutzner, C.; Van Der Spoel, D.; Lindahl, E. GROMACS 4: Algorithms for highly efficient, load-balanced, and scalable molecular simulation. J. Chem. Theory Comput. 2008, 4, 435-447. [CrossRef]

53. Parrinello, M.; Rahman, A. Polymorphic transitions in single crystals: A new molecular dynamics method. J. Appl. Phys. 1981, 52, 7182-7190. [CrossRef]

54. Bussi, G.; Donadio, D.; Parrinello, M. Canonical sampling through velocity rescaling. J. Chem. Phys. 2007, 126, 014101. [CrossRef] [PubMed]

55. Darden, T.; York, D.; Pedersen, L. Particle mesh Ewald: An N·log(N) method for Ewald sums in large systems. J. Chem. Phys. 1993, 98, 10089-10092. [CrossRef]

56. Hess, B. P-LINCS: A parallel linear constraint solver for molecular simulation. J. Chem. Theory Comput. 2008, 4, 116-122. [CrossRef] [PubMed]

57. Miyamoto, S.; Kollman, P.A. Settle: An analytical version of the SHAKE and RATTLE algorithm for rigid water models. J. Comput. Chem. 1992, 13, 952-962. [CrossRef]

58. Bonomi, M.; Branduardi, D.; Bussi, G.; Camilloni, C.; Provasi, D.; Raiteri, P.; Donadio, D.; Marinelli, F.; Pietrucci, F.; Broglia, R.A.; et al. PLUMED: A portable plugin for free-energy calculations with molecular dynamics. Comput. Phys. Commun. 2009, 180, 1961-1972. [CrossRef]

59. Kumar, S.; Rosenberg, J.M.; Bouzida, D.; Swendsen, R.H.; Kollman, P.A. Multidimensional free-energy calculations using the weighted histogram analysis method. J. Comput. Chem. 1995, 16, 1339-1350. [CrossRef]

60. Humphrey, W.; Dalke, A.; Schulten, K. VMD: Visual molecular dynamics. J. Mol. Graph. 1996, 14, 33-38. [CrossRef]

(C) 2020 by the authors. Licensee MDPI, Basel, Switzerland. This article is an open access article distributed under the terms and conditions of the Creative Commons Attribution (CC BY) license (http://creativecommons.org/licenses/by/4.0/). 